\title{
The effects of chronic lithium chloride administration on complex schedule performance, activity, and water intake in the albino rat
}

\author{
LINDA SMITH CRNIC \\ University of Illinois at Chicago Circle, Chicago, Ilinois 60680
}

\begin{abstract}
In an attempt to examine the behavioral effects of lithium, rats were trained on a multiple schedule consisting of fixed-ratio, fixed-interval, and time-out extinction requirements, and were subjected to lithium chloride in doses of $1.5,2.5$, and $3.0 \mathrm{meq} / \mathrm{kg} / \mathrm{day}$ administered for 15 days at a time. The performance on the 5 days preceding the drug was compared to the performance on the last 5 days of lithium treatment. While there was a significant increase in water consumption in the two higher dose groups, there was little effect on the schedule performance of the $2.5 \mathrm{meq} / \mathrm{kg}$ dose group and no effect upon the activity of any group. The $3.0 \mathrm{meq} / \mathrm{kg}$ dose tended to result in prolongation of the postreinforcement pauses on the fixed-ratio portions of the schedule and to truncate the fixed-interval response curve.
\end{abstract}

A common finding in lithium therapy of persons with manic depressive disorders is that the inappropriate high rate (manic) behaviors are improved, while normal activities and intellectual functions are not depressed (Ottoson, 1969). This raises the possibility that lithium acts selectively on behaviors which occur at high rates or acts on the manics' sense of timing of high rates. In this way, different rate behaviors within the same organism could be differentially affected.

One method of exploring this possibility is to assess the effects of lithium on stable performance on a multiple schedule involving a variety of rates of operant behavior. In this situation the different rates of behavior can be examined simultaneously in the same organism with the same level of lithium dosage and compared to that same organism's baseline of nondrug performance.

In the present experiment, the performance of rats on a multiple fixed-ratio, fixed-interval, time-out schedule was examined under three levels of lithium dosage given for 15 days at a time. While it is well known that the effects of lithium on humans do not begin to appear until an average of 10.3 days of chronic dosage (Fieve, Platman, \& Fleiss, 1969), probably because of the slow entry of lithium into the intracellular space (Singer \& Rotenberg, 1973), most animal research on the behavioral effects of lithium has involved acute or short-term doses. Thus, in the present study drug vs. baseline comparisons were made using the last. 5 days of baseline and the last 5 days of drug administration. Water intake served as a measure of the physiological effect of the drug, and activity in a stabili-

Reprints are available from the author at Box C233, The John F. Kennedy Child Development Center, B. F. Stolinsky Research Laboratories, University of Colorado Medical Center, 4200 East Ninth Avenue, Denver, Colorado 80220. The author wishes to thank Alexander J. Rosen for his advice and criticism of this study. meter was measured in order to determine if the effects upon operant behavior were nonspecific.

\section{METHOD}

\section{Subjects}

The subjects were 12 male Sprague Dawley rats 73 to 84 days old at the beginning of the experiment. They were kept in a continuously lit room with controlled temperature and humidity. The rats had continuous access to water and $11 / 2$ to $2 \mathrm{~h}$ access to Rockland rat chow each day. The food access was varied to maintain the rats at approximately $80 \%$ of their freefeeding weight. Because the attainment of stable baseline performance took months and because the rats would normally grow during this period, it was necessary to adjust the weights that the animals were held at in order to insure constant levels of deprivation. For this purpose, four of the rats were designated as weight controls and were allowed free access to food throughout the experiment. The data on the rate of weight gain of these nondeprived rats allowed adjustment of the weight ceilings of the experimental rats.

\section{Apparatus}

Daily water intake was measured by means of calibrated bottles which were read and refilled at the same time each day. Activity was measured by means of Lafayette (Model 86010) activity platforms which were set to record fine motor movements. The apparatus was controlled by BRS solid state programming equipment and the activity counts were printed on a Moduprint mechanical printer located in a different room than the platforms. The activity platforms were housed in a closed room lit with fluorescent tubes and isolated from the daily activity in the laboratory.

Two operant chambers (LVE Model 1316) equipped with response levers, pellet dispensers, cue lights above the levers, and houselights were enclosed in soundproofed chambers (LVE Model 1316c). Exhaust fans for the chambers provided masking noise. The experimental sessions were controlled by BRS solid state programming equipment and the animals' performance was recorded by Moduprint and BRS printout counters and Gerbrands cumulative recorders.

\section{Treatments}

The rats received doses of $1.5,2.5$, and $3.0 \mathrm{meq} / \mathrm{kg} / \mathrm{day}$ 
of lithium chloride dissolved in distilled water. The drug was given in divided doses twice a day by intraperitoneal injection. The doses were given in random order to each animal and were given for 15 days at a time, with at least 8 days in between the end of one dose trial and the beginning of the next.

\section{Procedure}

The general procedure was to gradually build the rats up on the operant schedule, run them to stability, give the first dose of the drug, restabilize, give the second dose, restabilize, and give the final dose. The rats differed in the way in which they were trained on the schedule, the time they took to attain stability, and the number of doses administered.

After magazine and barpress training, Subjects 1 to 4 were begun on a schedule of 20 fixed-ratio (FR) 1 reinforcements, 5 fixed-interval (FI) 1-min reinforcements, a 1-min time-out, and $20 \mathrm{FR} 1$ reinforcements, in that order, per session. The order of the schedule was kept invariant and each session lasted until all reinforcements were obtained. schedules were gradually attenuated to FR 24 and FI 2-min. It became apparent that stability of performance was going to be difficult to obtain with such a complex schedule, so the schedule was simplified to 20 FR 24, 5 FI 2-min, TO, 20 FR 24. The remaining animals $(6,7,11,12)$ were begun on the fixedratio schedule alone, worked up to FR 24 , and then the timeout (TO) and FI were added and the FI was gradually increased to FI 2-min. The schedule under which all animals received the drug doses consisted in each session of 20 FR 24 signaled by a flashing white cue light above the lever, 5 FI 2-min signaled by a steady cue light, a time-out of $1 \frac{1 / 2}{2}$ min during which no reinforcement could be obtained and which was signaled by a blackout of both the houselight and the cue light, and 20 FR 24 signaled by the flashing cue light. The sessions were run 7 days a week, at the same time each day, and began $1 \mathrm{~h}$ after the injection of half of the daily lithium dose. Immediately after the daily session, the animals were placed in the activity boxes for $15 \mathrm{~min}$ and then returned to their home cages. The rats were $14 \mathrm{~h}$ without food at the beginning of their experimental sessions.

\section{RESULTS}

The high $(3.0 \mathrm{meq} / \mathrm{kg})$ dose was toxic to some of the animals $(2,7,11)$ and was discontinued before 15 days because diarrhea clearly threatened the animals' wellbeing. Three of the weight control animals and two experimental subjects ( 1 and 6$)$ died of respiratory infections. The two experimental subjects died before any drug trials were given. Two experimental subjects (2 and 3) died after two drug trials each, the latter of uremic poisoning subsequent to bladder rupture by bladder stones. Three of the animals $(4,11$, and 12) did not receive all of the doses because of the extensive times necessary to establish baseline performance.

Water intake for each dose averaged over animals is shown in Figure 1. The group curves are representative of all of the animals. The increase in drinking did not start until aiter 4 days of administration of lithium. The extent of the polydipsia was a function of the dose. The difference between the baseline water intake and the water intake on the last 5 days of drug administration was found to be statistically significant for the medium and high doses by $t$ tests (Table 1 ). Water intake peaked at 7 to 11 days in the individual animals, followed by a decrease in water intake.

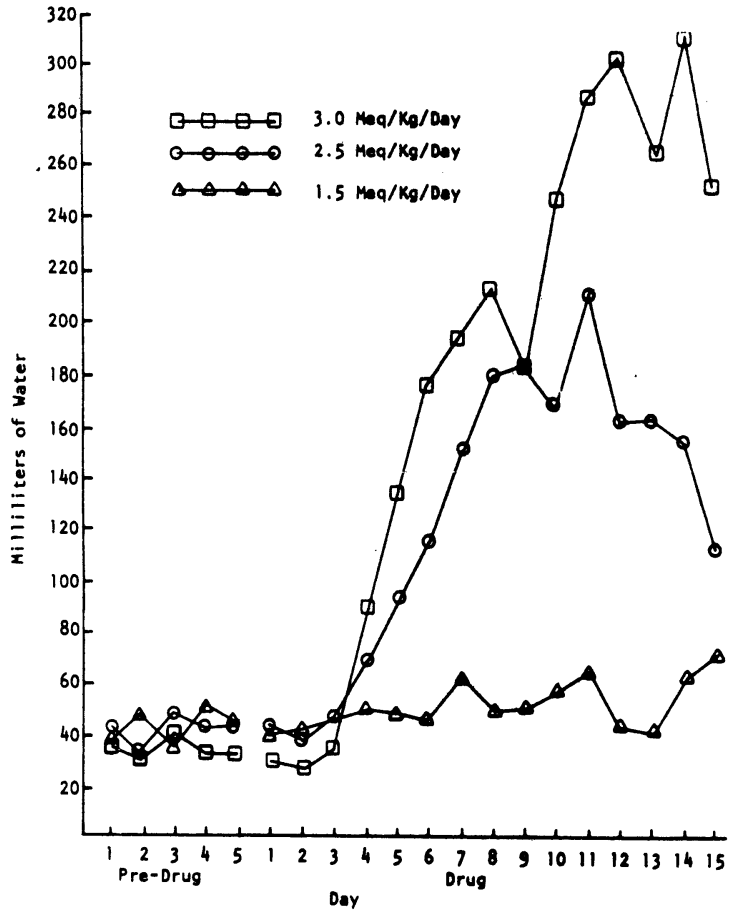

Figure 1. Water intake in milliliters during the 5 baseline and 15 lithium administration days. Curves represent group averages.

Activity scores for the group data for the three drug doses are shown in Figure 2. $t$ tests revealed no significant difference between baseline activity levels and activity during the last 5 days of drug dosage (Table 1). For the high and medium doses, the trend was toward a depression in activity for the first 6 days of drug administration followed by a return to baseline levels. Analyses of the baseline vs. drug variances revealed no

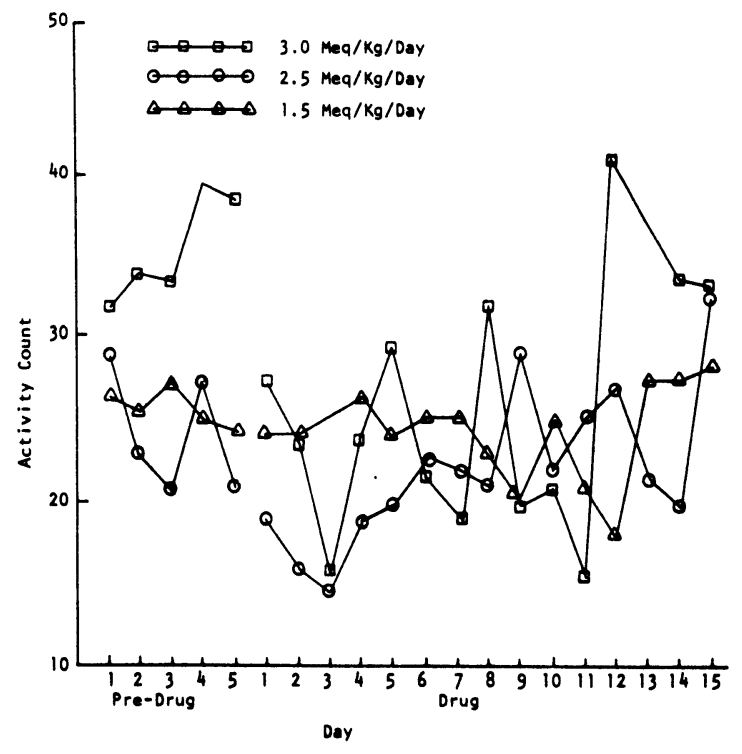

Figure 2. Activity counts for 5 baseline and 15 lithium administration days. Curves represent group averages. 
Table 1

Difference Between 5 Days Baseline and Last 5 Days Drug Administration Divided by the Estimate of the Population Standard Deviation

\begin{tabular}{|c|c|c|c|c|c|c|c|c|c|c|}
\hline \multirow[b]{2}{*}{ Measure } & \multicolumn{4}{|c|}{$\begin{array}{c}1.5 \mathrm{Meq} / \mathrm{kg} / \mathrm{day} \\
\text { Subject }\end{array}$} & \multicolumn{4}{|c|}{$\begin{array}{c}2.5 \mathrm{Meq} / \mathrm{kg} / \mathrm{day} \\
\text { Subject }\end{array}$} & \multicolumn{2}{|c|}{$\begin{array}{c}3 \mathrm{Meq} / \mathrm{kg} / \text { day } \\
\text { Subject }\end{array}$} \\
\hline & 2 & 3 & 4 & 7 & 2 & 4 & 7 & 11 & 3 & 12 \\
\hline FR Response Rate & -2.93 & -.32 & -1.09 & -2.93 & -3.60 & -3.02 & -2.11 & -2.22 & $-7.16^{*}$ & -.27 \\
\hline $\begin{array}{l}\text { Responses During } \\
\text { First Quarter FI }\end{array}$ & -.96 & -1.11 & +.22 & +1.93 & -1.33 & +1.22 & -.11 & +.68 & +.23 & +1.11 \\
\hline $\begin{array}{l}\text { Responses During } \\
\text { Second Quarter FI }\end{array}$ & +1.52 & +1.06 & +1.68 & -.32 & +1.78 & +1.04 & +1.64 & +1.26 & 0 & +3.45 \\
\hline $\begin{array}{l}\text { Responses During } \\
\text { Third Quarter FI }\end{array}$ & +.29 & +.69 & +.45 & +.14 & -2.06 & +.63 & +.70 & -.76 & $-6.20 *$ & $-4.21^{*}$ \\
\hline $\begin{array}{l}\text { Responses During } \\
\text { Fourth Quarter FI }\end{array}$ & -1.93 & -1.03 & +.22 & +.35 & $-5.40^{*}$ & +.79 & +.16 & -2.08 & $-14.11^{*}$ & +3.00 \\
\hline $\begin{array}{l}\text { Responses During } \\
\text { Time Out }\end{array}$ & -1.99 & +2.43 & -2.28 & +.36 & -.09 & +.62 & +.40 & +.32 & -1.43 & -.40 \\
\hline $\begin{array}{l}\text { Index of Curvature } \\
\text { Water Intake } \\
\text { Activity }\end{array}$ & $\begin{array}{r}-1.62 \\
+2.75 \\
+.41\end{array}$ & $\begin{array}{l}-1.10 \\
+3.63 \\
+1.34\end{array}$ & $\begin{array}{r}-2.33 \\
+.75 \\
-.93\end{array}$ & $\begin{array}{r}+.34 \\
+1.08 \\
-2.67\end{array}$ & $\begin{array}{l}-6.09 * \\
+5.79 * \\
+2.39\end{array}$ & $\begin{array}{c}-1.49 \\
+11.12 * \\
+.70\end{array}$ & $\begin{array}{l}-.92 \\
+6.77 * \\
+.24\end{array}$ & $\begin{array}{l}-2.10 \\
+5.24 * \\
+.04\end{array}$ & $\begin{array}{c}-4.23 * \\
+10.67 * \\
+1.34\end{array}$ & $\begin{array}{l}-.82 \\
+4.98 \\
-1.79\end{array}$ \\
\hline
\end{tabular}

*Significant by $t$ test, $\gamma=8, \alpha=.002$, two-tailed test. $\alpha$ was set low because of the large number of tests.

significant increases in variability in performance on the last 5 days of drug dosage.

Table 1 presents the changes between baseline and the last 5 days of lithium dosage, given as a function of the estimate of the population standard deviation based on the standard deviations of the two 5-day samples. It is obvious that there is a great deal of intersubject variability. The lithium had no appreciable effects at the low dose, affected little more than water intake at the medium dose, and affected only one of the subjects at the high dose. Under the medium dose, only Subject 2 showed effects in measures other than water intake. For this animal the lithium significantly decreased the number of responses made in the fourth quarter of the fixed intervals and decreased the index of curvature, a measure of the positive acceleration of the fixed-interval response curves ${ }^{1}$ (Fry, Kelleher, \& Cook, 1960). The high dose, which was toxic to three of the subjects on which it was tried, produced a decrease in the FR rate and the index of curvature in Subject 3 , a decrease in responding during the third quarter of the fixed-interval responding for Subjects 3 and 12 , and a decrease in fourth-quarter responding in Subject 3. The differences in the FR rates in all cases were due to an increase in the length of postreinforcement pauses rather than a decrease in the rate when responding. The change in the fixed intervals consisted of a truncation of the normal increase in response rate near the end of each interval (Figure 3).

\section{DISCUSSION}

The intersubject variability, for example, that between Subjects 3 and 12 on the high dose, must temper the conclusions that can be drawn. While only one subject showed a significant decrease in fixed-ratio response rate, the direction of all animals on all doses was toward a decrease in rate. The decrease consisted of an increase in the length of the postreinforcement pauses rather than a decrease in responding when the animal was responding. During the fixed-interval schedule, three animals showed significant decreases in responding during the second half of the interval. That this was not caused by fatigue or a decrease in activity is indicated by the fact that the responding during the first half of the intervals was not decreased but in most cases was higher and the fact that the activity was not decreased by lithium during the last 5 days of administration.

It is not entirely clear what these findings indicate for the hypothesis that lithium acts selectively on high rate behaviors or on timing. The effects of lithium on the fixed-interval performance may be evidence that high rates during the interval are more susceptible to drug effects but the relative lack of change in the fixed-ratio responding is not. This may be explained

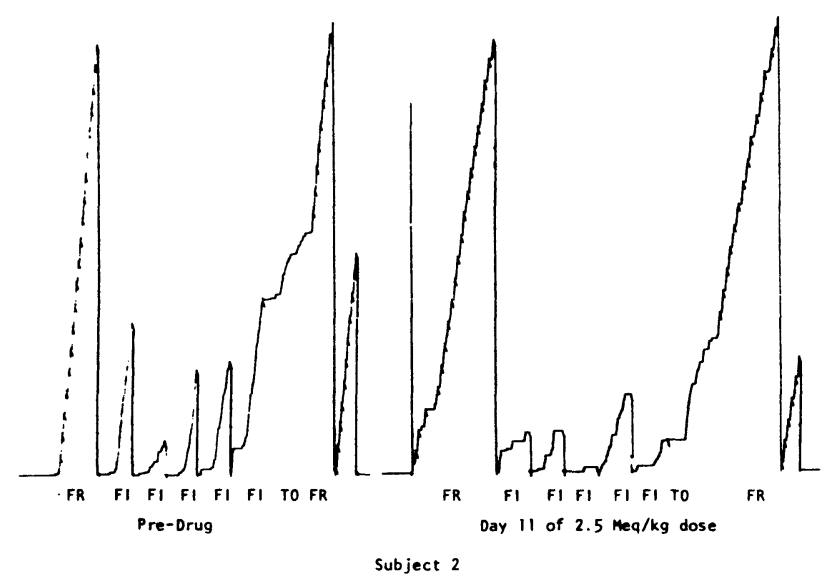

Figure 3. Cumulative records of predrug and 11 th day of drug administration for Subject 2, medium dose. 
by the common finding that fixed-ratio rates are relatively inflexible in comparison to other schedules (Sidman, 1960).

Two steps might be taken in future research to reduce variability in this type of paradigm. First, although complex multiple schedules possess attractive advantages in the design of experiments, their very complexity makes attainment of stable baselines difficult and prolongs experiments to the extent that they must take up the majority of the normal life-span of the laboratory rat. Two solutions to these problems are possible. The first is to reduce the complexity of the schedule and the second is to use subjects with higher intelligence and longer life-spans. A second measure that might be taken is to assign animals to groups on the basis of their serum lithium levels rather than dose because the retention of lithium of animals given the same dose may vary by as much as $100 \%$ to $200 \%$ (Schou, 1969).

Two features of the water intake curves are of interest in light of previous research. First, the water intake did not rise immediately after the onset of lithium treatment but was delayed for 3 days. This is in contrast to the finding by Smith and Balagura (1972) that a single dose of lithium in the same range of dosage as used here produced an immediate increase in water intake. No explanation is available for this difference, except that Smith and Balagura deprived their rats of water before testing. The second feature of interest is the fact that water intake peaked at 7 to 11 days in the individual animals and thereafter showed a decrease. This peak in water intake occurs at the time at which lithium completes its equilibration within the intracellular space (Singer \& Rotenberg, 1973) and at the time at which manic behavior begins to be controlled in humans (Fieve et al., 1969). In future research, instead of looking at behavioral effects after a fixed number of days of drug administration, it might be best to look at behavior after water intake has peaked, since there was variability in the time at which the individual animals' water intake peaked.

The failure to find a decrease in activity is in contrast to many studies of the effects of lithium upon activity (Carroll \& Sharp, 1971; Johnsón, 1971; Matussek \& Linsmayer, 1968; Smith \& Smith, 1973; Syme \& Syme, $1973,1974)$, but is probably easily explained. In all cases, these studies involved lithium administration for less than 10 days, while the present study looked at effects only after the 10th day of administration. The graph of the lithium effects upon activity (Figure 2) in the present experiment shows an initial decrease in activity lasting several days, followed by an increase in activity to baseline levels. Thus, short-term lithium administration may reveal a decrease in activity, while long-term administration would not. That this may be the case is indicated by a study by Cox, Harrison-Read,
Steinberg, and Tomkiewicz (1971) on the effects of lithium on hyperactivity induced by a combination of chlordiazepoxide and dextroamphetamine in rats. They found that acute doses of lithium attenuated the drug-induced hyperactivity, while chronic doses spanning 15 days did not differ from saline in its effectiveness. This difference between acute and chronic doses of lithium parallels the finding of Schildkraut (1974) that short-term administration of lithium results in an increase in the turnover of norepinephrine in the rat brain due to enhanced intraneuronal release, but that long-term (greater than 2 weeks) administration does not result in such an increase in turnover. Corrodi, Fuxe, and Schou (1969) and Ho, Loh, Craves, Hitzeman, and Gershon (1970) confirm this latter finding. These findings emphasize the necessity of examining behavior during long-term dosages if animal research is going to elucidate the mechanism of lithium action upon mania.

\section{REFERENCES}

Carroll, B. J.. \& Sharp, P. T. Rubidium and lithium: Opposite effects on amine-mediated excitement. Science, $1971,172,1355-1357$.

Corrodi, H., Fuxe, K., \& Schou, M. The effect of prolonged lithium administration on cerebral monoamine neurons in the rat. Life Sciences, 1969, 8, 643-651.

Cox. C.. Harrison-Read, P. E., Steinberg, H., \& Tomkiewicz, M. Lithium attenuates drug-induced hyperactivity in rats. Nature, 1971, 232, 336-337.

Fieve. R. R., Platman, S. R., \& Fleiss, J. L. A clinical trial of methysergide and lithium in mania. Psychopharmacologia, $1969,15,425-429$.

Fry, W., Kelleher, R. T., \& Cook, C. A mathematical index of performance on fixed-interval schedules of reinforcement. Journal of the Experimental Analysis of Behavior, 1960. 3. 193-199.

Ho. A. K. S.. Loh, H. H., Craves, F., Hitzeman, R. J., \& Gershon. S. The effect of prolonged lithium treatment on the synthesis rate and turnover of monoamines in brain regions of rats. European Journal of Pharmacology, 1970, 10, 72-78.

Johnson, F. N. Dissociation of vertical and horizontal components of activity in rats treated with lithium chloride. Experientia, 1971, 28, 533-535.

Matussek, N., \& Linsmayer, M. The effect of lithium and amphetamine on desmethylimipramine-R04-1284 motor hyperactivity. Life Sciences, 1968, 7, 371-375.

Otroson, J. O. Introduction: Lithium in psychiatry. Acta Psychiatrica Scandinavica, 1969, Supplement 207, 9-11.

SChILDKRaUt, J. J. The effects of lithium on norepinephrine turnover and metabolism: Basic and clinical studies. Journal of Nervous and Mental Disease, 1974, 158, 348-360.

Schou. M. Lithium: Elimination rate, dosage, control, poisoning, goiter, mode of action. Acta Psychiatrica Scandinavica, 1969, Supplement 207, 49-54.

Sidman, M. Tactics of scientific research. New York: Basic Books, 1960.

Singer, I., \& Rotenberg, D. Mechanism of lithium action. New England Journal of Medicine, 1973, 289, 254-260. 
Smith, D. F., \& Balagura, S. Sodium appetite in rats given lithium. Life Sciences. 1972, 11, 1021-1029.

Smrth, D. F., \& SMrrh, H. B. The effect of prolonged lithium administration on activity, reactivity, and endurance in the rat. Psychopharmacologia, 1973, 30, 83-88.

Syme, L. A.. \& SYme, G. J. Effects of $\mathrm{LiCl}$ on the activity of rats tested alone or in pairs. Psychopharmacologia, 1973, 29. 85-89.

Syme, L. A., \& Syme, G. J. The role of sex and novelty in determining the social response to lithium chloride. Psychopharmacologia, 1974, 40, 91-100.

\section{NOTE}

1. Index of curvature:

$$
I=\frac{3 R_{4}-2\left(R_{1}+R_{2}+R_{3}\right)}{4 R_{4}}
$$

where $R_{1}$ is the number of responses made in the first quarter of the interval, $R_{2}$ is the number of responses made in the first and second quarters of the interval, $R_{3}$ is the number of responses made in the first, second, and third quarters of the interval, and $R_{4}$ is the number of responses made in the entire interval.

(Received in Austin October 29, 1975.) 